\title{
Gold Catalysis: A Reflection on Where We are Now
}

\author{
Simon J. Freakley • Qian He • Christopher J. Kiely • \\ Graham J. Hutchings
}

Received: 22 October 2014 / Accepted: 12 November 2014/Published online: 23 November 2014

(C) Springer Science+Business Media New York 2014

\begin{abstract}
Heterogeneous catalysis by gold is now a very well established research topic and several thousands of papers have appeared since the pioneering studies based on $\mathrm{CO}$ oxidation and acetylene hydrochlorination reactions in which, for the first time, supported gold catalysts were shown to be the best catalysts for these reactions. It is now widely recognised that gold either by itself or in combination with other metals is an excellent redox catalyst. In particular gold-containing catalysts are very effective for the selective oxidation of alcohols. Initially it was considered that base was needed to be present for alcohols to be effectively oxidised but efficient catalyst design has enabled alcohols to be oxidised to aldehydes without the need for added base. Gold-containing catalysts are also exceptionally effective for the hydrogenation of oxygen to form hydrogen peroxide. This direct synthesis route shows great potential for a number of applications at this time. More recently gold-containing catalysts have been shown to be effective in $\mathrm{C}-\mathrm{H}$ activation reactions. Due to the ever increasing opportunities for applying heterogeneous gold catalysts, interest in how effective catalysts are designed and synthesised remains strong. In this paper both the early work and the more recent discoveries concerning heterogeneous catalysis by gold will
\end{abstract}

\footnotetext{
S. J. Freakley · G. J. Hutchings $(\square)$

Cardiff Catalysis Institute, School of Chemistry, Cardiff

University, Main Building, Park Place, Cardiff CF10 3AT, UK

e-mail: hutch@cf.ac.uk; Hutch@cardiff.ac.uk

Q. He · C. J. Kiely

Department of Materials Science and Engineering, Lehigh

University, 5 East Packer Avenue, Bethlehem, PA 18015-3195, USA
}

be considered and some suggestions on the way forward will be presented.

Keywords Heterogeneous catalysis - STEM · Impregnation

\section{Introduction}

It is apt that gold catalysis is included as a topic in the silver jubilee issue of Catalysis Letters. This is because the timeline for the discovery of gold as a high activity heterogeneous catalyst goes back to the period just before the advent of Catalysis Letters and during the intervening 25 year period gold catalysis has been continually advancing as a research topic. In the early years there was only limited interest in the subject but as time went on and new discoveries were made, so the field of gold catalysis has expanded dramatically. In this perspective article we will concern ourselves solely with gold as a component of heterogeneous catalysts. There has been a parallel development with the use of gold as a homogeneous catalyst for which many new and exciting catalysis developments have been identified $[1,2]$. The field of heterogeneous gold catalysis was sparked by two contemporaneous discoveries made by Haruta [3] and Hutchings [4] concerning low temperature $\mathrm{CO}$ oxidation and acetylene hydrochlorination respectively; for both reactions gold was not only found to be highly active, but it was also shown to be the best catalyst. Prior to this gold had been considered a metal that offered relatively low catalytic potential in the heterogeneous state, meaning that the field of gold catalysis experienced a relatively low pace of development in the early years. Subsequently there has been a continuous sequence of discovery of new catalysis applications for gold and goldcontaining catalysts. These have included:- 
1996 Epoxidation of propene using Au supported on titanium oxides [5].

1998 Oxidation of alcohols using supported Au catalysts in basic media [6].

2002 Oxidation of glycerol using supported Au catalysts in basic media [7].

2002 Direct synthesis of hydrogen peroxide using Aucontaining catalysts [8].

2003 Low temperature water gas shift catalysis with supported gold catalysts [9].

2005 Oxidation of alcohols in the absence of base with supported Au catalysts [10].

2005 Epoxidation of alkenes in liquid phase reactions [11].

2006 Selective hydrogenation of nitro compounds [12]. 2006 AuPd alloy catalysts give enhanced activity in alcohol oxidation [13].

2009 AuPd alloys active for $\mathrm{H}_{2} \mathrm{O}_{2}$ synthesis but not for $\mathrm{H}_{2} \mathrm{O}_{2}$ hydrogenation [14].

2010 AuPt alloys active for glycerol oxidation in the absence of base [15].

2011 AuPd alloys active for toluene oxidation to benzoyl benzoate [16].

2013 Methane oxidation with $\mathrm{H}_{2} \mathrm{O}_{2}$ catalysed by AuPd alloys [17].

2014 AuPdPt trimetallic catalysts highly active for alcohol oxidation [18].

Without doubt there are many more discoveries concerning gold catalysis that will be made in the coming years. In the early work it was identified that the method by which the gold catalysts are prepared plays a vital role in determining the activity for particular reactions. This is particularly true for $\mathrm{CO}$ oxidation where it was found that the co-precipitation and deposition precipitation methods enabled catalysts to be prepared that comprised small nanoparticles [3, 19]. Initially it was considered that the high activity observed with gold was related solely to the nanoparticle size with the smaller nanoparticles exhibiting the highest activity [20]. With the advent of aberrationcorrected STEM, however, it became apparent that gold catalysts exhibited a very complex mix of morphologies with single atoms, monolayer clusters, bilayer clusters and small nanoparticles all being present [21] and for $\mathrm{Au}$ supported on iron oxide there was evidence to suggest that the high activity for $\mathrm{CO}$ oxidation was associated with the small bilayer clusters [22]. However, with bimetallic AuPd catalysts there is an additional complexity in that there is usually a variation in the $\mathrm{Au}: \mathrm{Pd}$ ratio from particle-to-particle that changes systematically with particle size, and that the type and severity of this composition variation is also a function of the preparation method [23].
Hence it is apparent that gold catalysis is a field of study for which the catalysts exhibit a very high degree of complexity. Of course this is a topic where model studies can provide great insights, but in this perspective article we will concern ourselves with relatively high area catalysts. If the activity for a particular reaction is associated with a specific morphology of gold, e.g. the small bilayer structures, and there is only a relatively low concentration of these species present, it is entirely possible that most of the gold present in the catalyst is inactive or at best is not in a form that displays optimal activity. This means that there is an immense potential for progressing gold catalysis by improving the catalyst preparation method alone. In this perspective article we will explore the possibilities for the future development of gold catalysis and we will speculate on the possible advances that can be expected in the next 25 years.

\subsection{Preparation of Supported Au and Au-Containing Nanoparticles}

There are many ways by which supported Au nanoparticles can be prepared. These methods include impregnation [13], modified impregnation [24], sol-immobilisation [18], coprecipitation [19], and deposition precipitation [3]. All can make effective catalysts, but the catalysts tend to have very different morphologies:

- Impregnation: (1-25 nm nanoparticles, often multiply twinned + atoms\& clusters $)^{*}$.

- Modified impregnation: (1-10 nm nanoparticles,)*.

- Co-precipitation: (1-10 nm nanoparticles, + atoms\& clusters) $\dagger$.

- Deposition precipitation: (1-10 nm nanoparticles +atoms\& clusters)*.

- Sol-immobilisation: (2-6 nm nanoparticles)*.

* Support is pre-formed.

$\uparrow$ Support is formed during the preparation.

It is the advent of aberration-corrected scanning transmission electron microscopy that has enabled the microstructures of supported metal nanoparticles to be observed in significant detail $[21,22]$. The complexity of the species present on the surface of gold-containing catalysts can be exemplified by contrasting impregnation and modified impregnation methods of preparation for AuPd catalysts. Impregnation is the simplest way of making supported metal nanoparticles. In this method $\mathrm{HAuCl}_{4}$ and $\mathrm{PdCl}_{2}$ are dissolved in water and the support is added to form a wet paste that is then dried and calcined. In the modified impregnation method [24] additional halide is added to the initial solution and all other steps remain the same except that the calcination step is replaced by a reduction step to 
remove excess halide. The morphologies of these two materials when studied by aberration-corrected STEM appear to be very similar. However, the impregnation method does not effectively disperse the gold component and a size dependent composition is observed with the smallest nanoparticles always being palladium rich. The size-dependent composition variation is not observed with the modified impregnation method and the nanoparticles all have a similar composition because in this case the preparation method effectively disperses both the gold and the palladium components. However, it is clear that these impregnation methods lead to a range of nanostructures including atoms, monolayer clusters, bilayer clusters and small nanoparticles (Fig. 1). These species are also observed with co-precipitation and deposition precipitation (Fig. 2). It is only with the sol-immobilisation method that one observes only a narrow dispersion of nanoparticles without the formation of highly dispersed atoms and clusters (Fig. 3).

When used as catalysts it is possible that all these metallic species will display some degree of activity and we suspect that there may be a distinct hierarchy of activities for these species. The challenge that faces this field is to evaluate if practical catalyst preparation methodologies can be designed that yield materials with very specific morphologies so that the effectiveness of the most active component can be maximised. Of course the microstructures discussed so far should be considered as catalyst precursors, since under reaction conditions it is feasible that the materials can restructure forming new shapes and surface facets. One question that is uppermost in this field concerns the role of the support. In many reactions it is not merely acting as a benign surface on which the active metallic species are supported. This has been clearly demonstrated in many reactions as the support can affect the observed activity markedly [1].

\subsection{Au Catalysts and Improving Catalysyt Activity}

A key reaction for which gold catalysis holds much potential is acetylene hydrochlorination for the production of vinyl chloride monomer. The discovery that gold would be an effective catalyst for this reaction was based on a correlation with the standard electrode potential and this was confirmed by subsequent experimental work [4, 25]. This reaction is starting to receive significant attention and
Fig. 1 HAADF STEM micrographs of $\mathrm{AuPd} / \mathrm{TiO}_{2}$ prepared by a conventional impregnation and $\mathbf{b}$ the modified impregnation method in which the co-existence of $\mathbf{a}$, c AuPd nanoparticles and b, d sub-nm Pd-rich clusters and atomically dispersed $\mathrm{Au} \& \mathrm{Pd}$ is apparent
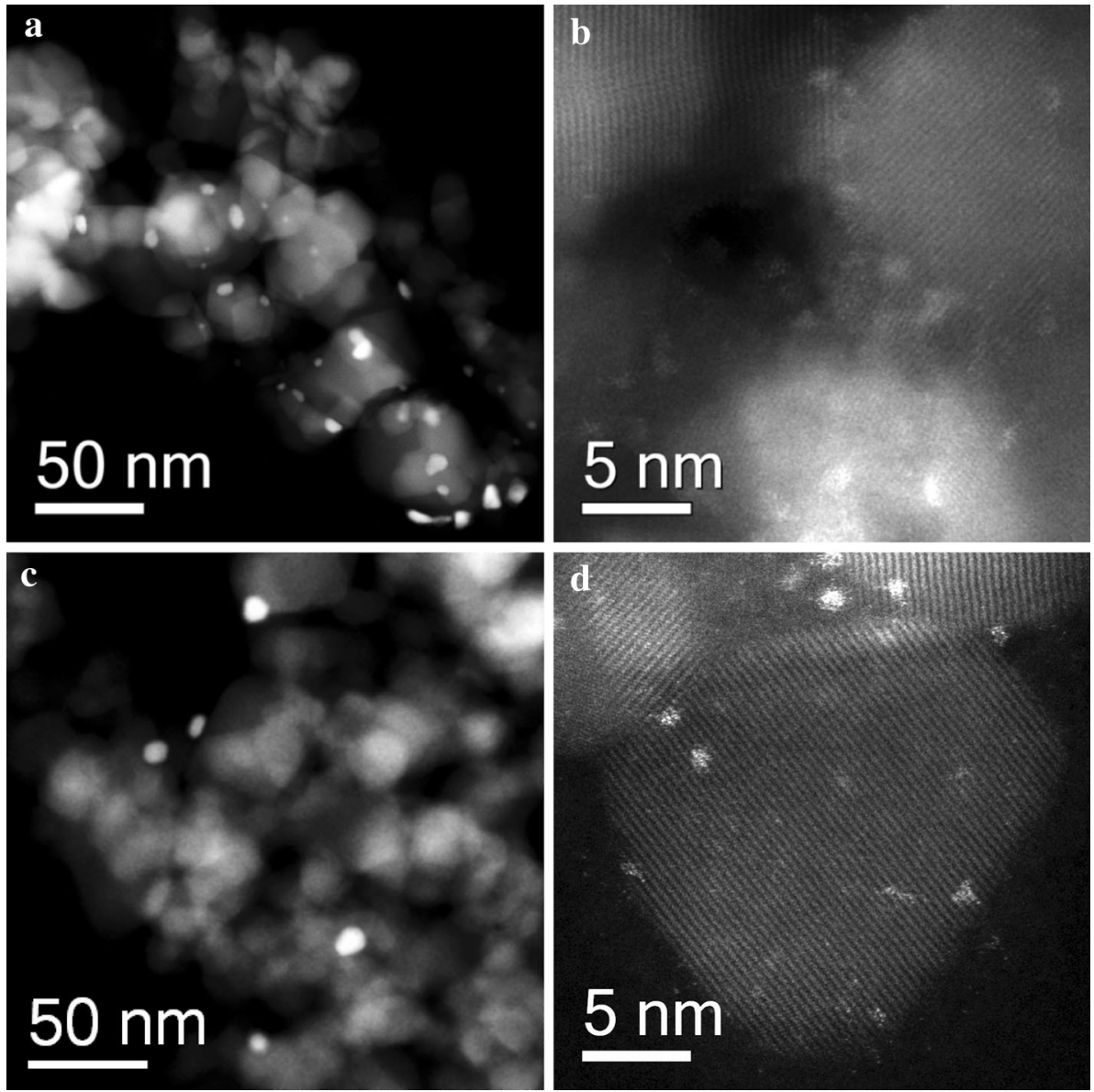

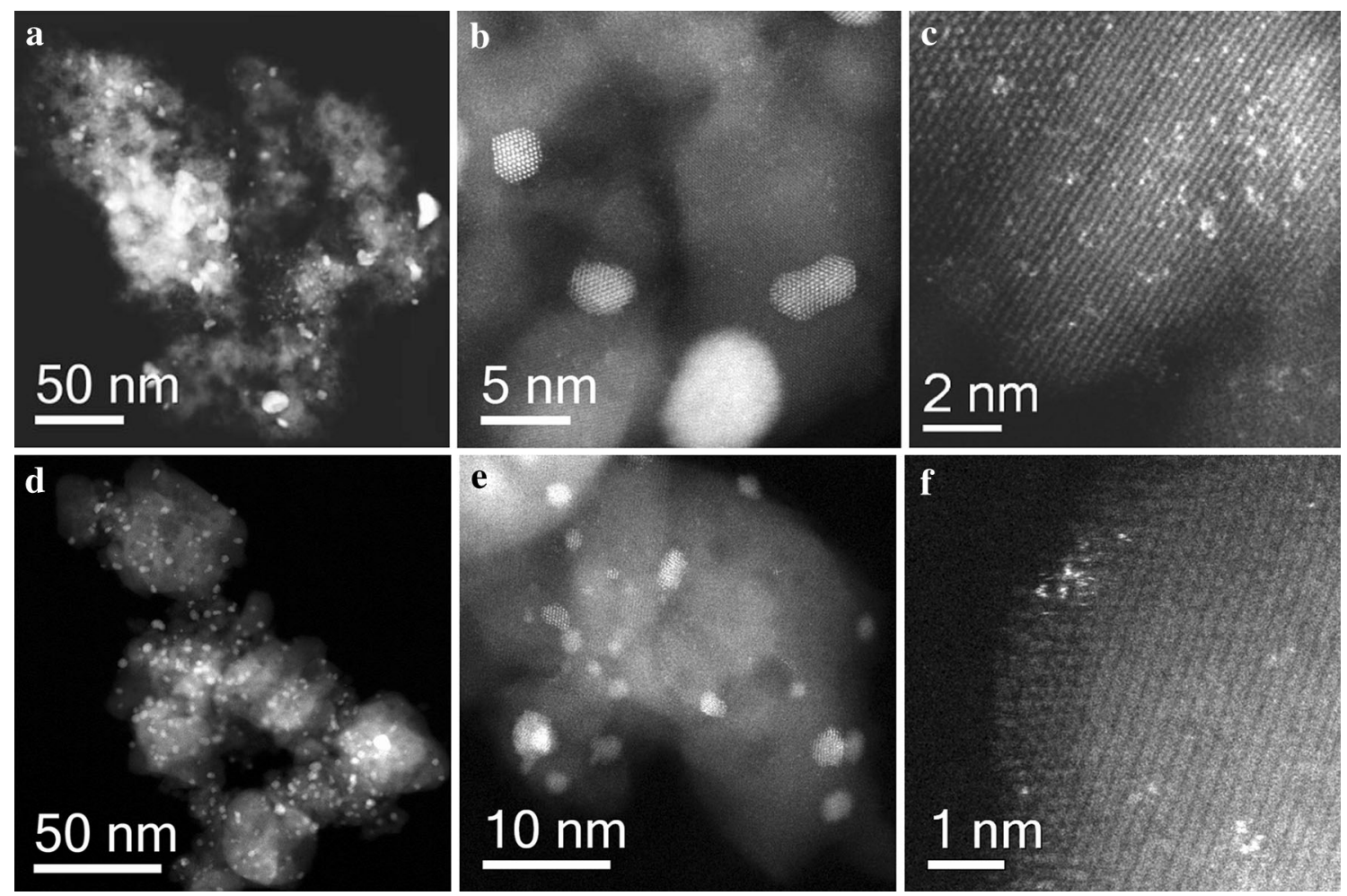

Fig. 2 HAADF STEM micrographs of $\mathrm{Au} / \mathrm{TiO}_{2}$ prepared by $\mathbf{a}, \mathbf{b}, \mathbf{c}$ the co-precipitation method and $\mathbf{d}$, e, $\mathbf{f}$ the deposition precipitation method. For both these routes the co-existence of Au nanoparticles (in $\mathbf{a}, \mathbf{b}, \mathbf{d}$ ), sub-nm clusters (in $\mathbf{b}, \mathbf{e}$ ) and individual Au atoms (in $\mathbf{e}, \mathbf{f}$ ) can be seen

Fig. 3 a BF-TEM and b HAADF STEM micrographs of $\mathrm{Au} / \mathrm{TiO}_{2}$ prepared by the solimmobilisation method for which a narrow dispersion of nanoparticles occurs without the formation of highly dispersed atoms and clusters
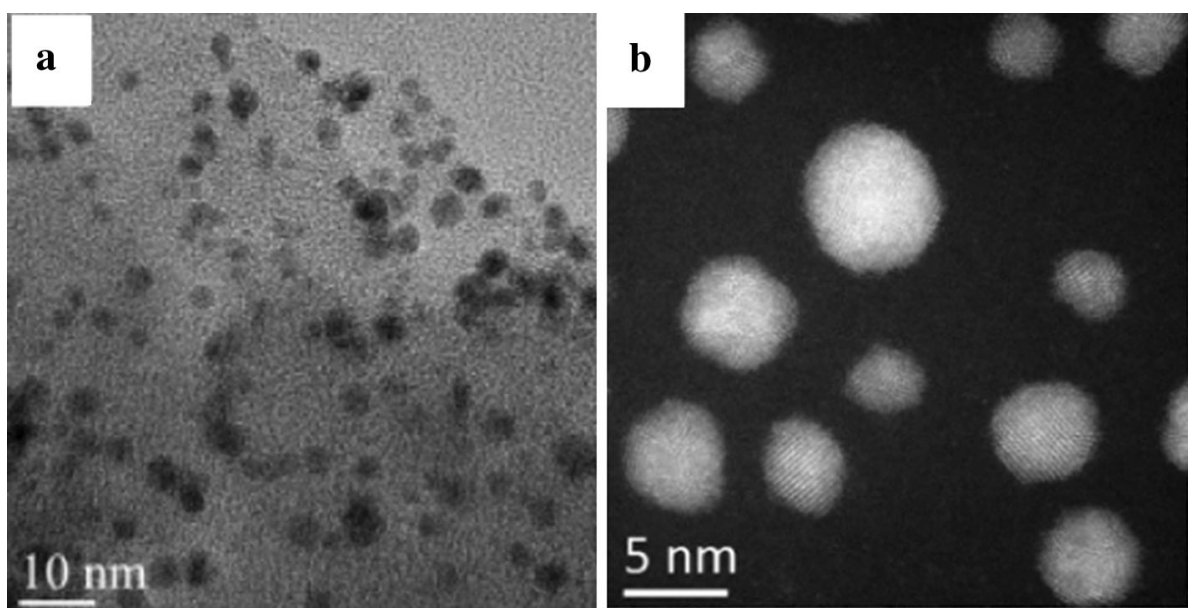

so there is now significant interest in improving the catalyst activity. One method that has been employed to great effect in many reactions concerns the addition of a second metal that can form an alloy, e.g. palladium; this alloying strategy will be discussed for a number of reactions subsequently. In the case of acetylene hydrochlorination this strategy is ineffective. Any dilution of gold by palladium, or other metals, leads to a loss of activity [26]. Indeed, at present gold-only catalysts still present the highest activity. Another interesting observation concerning this reaction is that carbon is the only effective support. Replacement of carbon with other supports tends to lead to an inactive catalyst. This probably suggests a very strong influence of the support and that the peripheral sites where the gold species interact with the carbon surface are the active species. A key observation for gold catalysts in this reaction is the overall selectivity as vinyl chloride is formed extremely selectively and other products are not observed that result from the subsequent addition of hydrogen chloride to vinyl chloride. This is certainly not the case 
with other catalysts, e.g. mercuric chloride, where significant amounts of by-products are observed. Indeed this high specificity of gold for carbon-carbon triple bonds has been exploited in many reactions catalysed by homogeneous gold species [1].

In the seminal studies by Prati and Rossi in 1996 [6] it was observed that supported gold nanoparticles could be effective for the oxidation of alcohols in the presence of base. The base was crucial with gold-only catalyst formulations and it was reasoned that the base activated the alcohol by abstraction of a hydroxyl hydrogen thereby enabling oxidation to proceed. Very high specificities to acids could be achieved with this methodology. Of course the need for the strong base, e.g. $\mathrm{NaOH}$, proves to be a disadvantage as the reaction products are the salts of the acid and this limits its application. Corma and co-workers [10] in 2005 showed that careful preparation of gold nanoparticles supported on ceria gave a catalyst that was highly effective in the absence of base. Clearly once again the interaction of the metal with the support, in this case a redox active oxide, is important in forming an active catalyst. For the oxidation of alcohols the addition of a second metal is a particularly effective strategy in catalyst design. In particular, the addition of palladium to form $\mathrm{Au}-\mathrm{Pd}$ alloy particles leads to an enhancement in activity by a factor of ca. 27 compared with the gold-only and
Fig. 4 a Low magnification HAADF image, b Au elemental map and $\mathbf{c}$ Pd elemental map of a $\mathrm{AuPd} / \mathrm{TiO}_{2}$ catalyst prepared by impregnation showing that the larger particles are gold-rich whereas the smaller ones are Pd-rich. d Au elemental map, e Pd elemental map and f overlaid $\mathrm{Au}$ (blue), $\mathrm{Pd}$ (green) and Ti (red) of a larger alloy particle in a $\mathrm{AuPd} / \mathrm{TiO}_{2}$ catalyst showing that it has a Au-rich core and Pd-rich shell structure
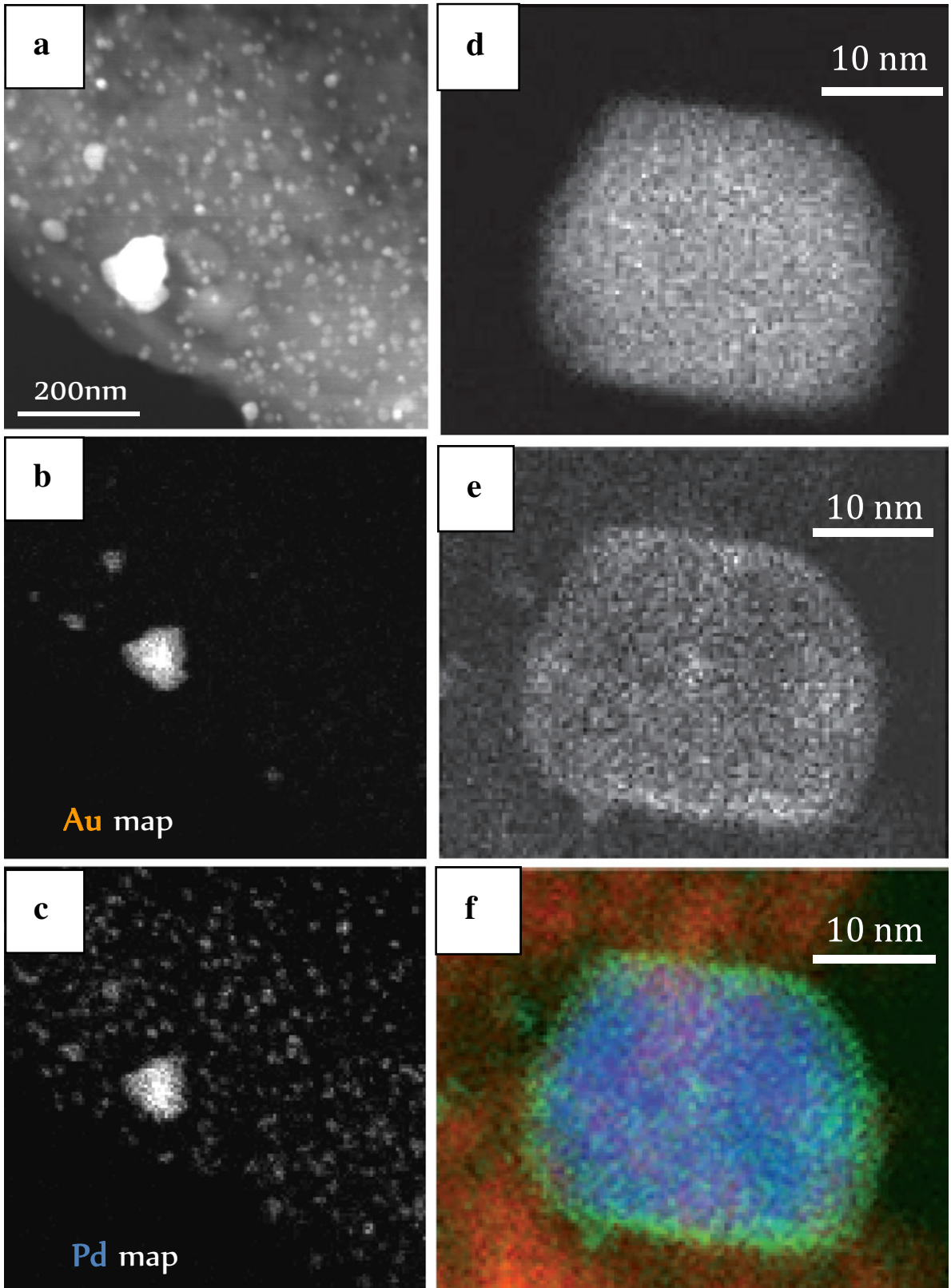
Fig. 5 Low magnification a BF-TEM and b HAADF STEM micrographs of supported AuPd nanoparticles prepared by the solimmobilisation method illustrating their narrow metal size dispersion. Higher magnification HAADF images of individual random alloy AuPd alloys particles show them to have either c cuboctahedral or $\mathbf{d}$ icosahedral arrangements of atoms
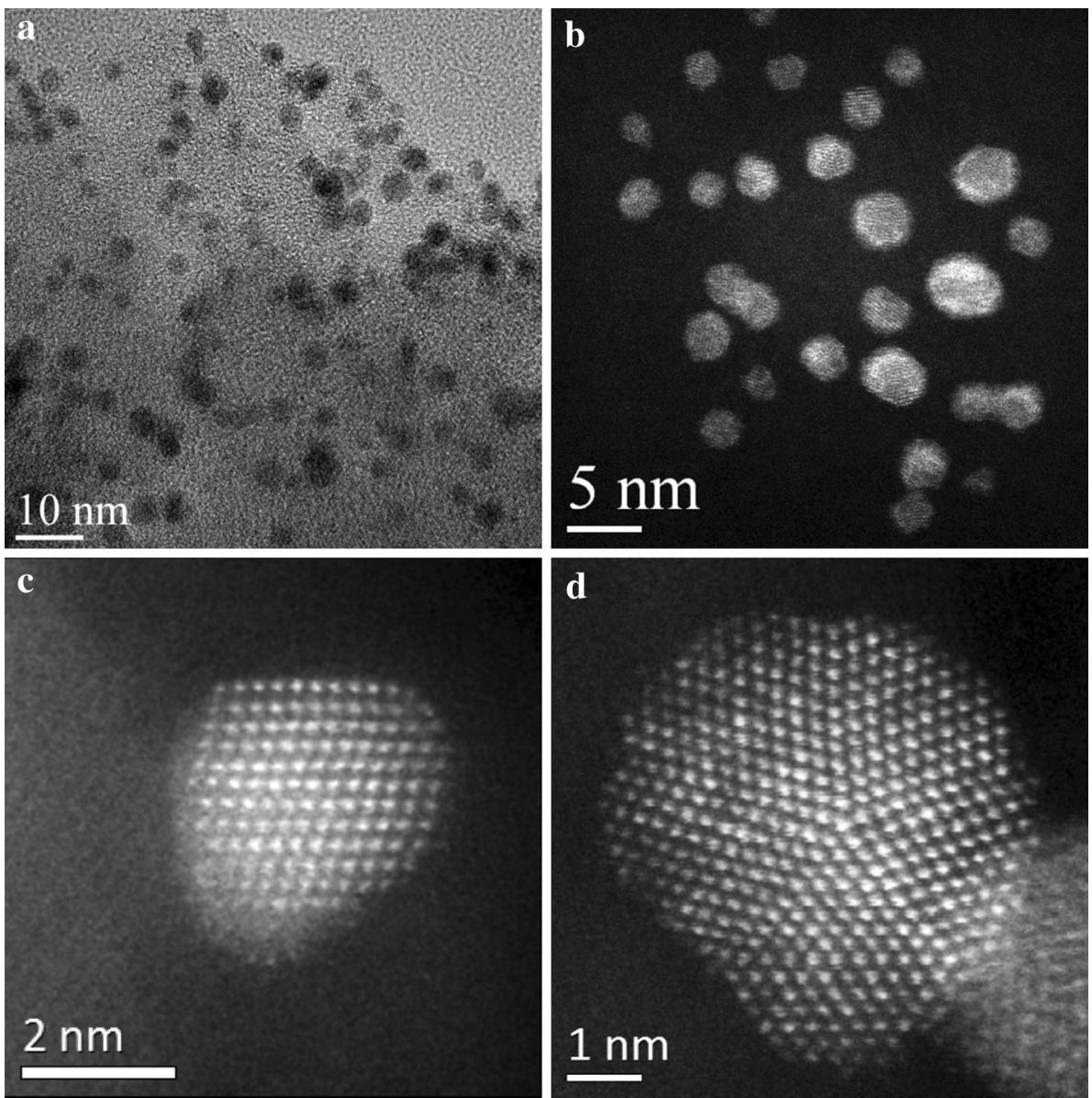

palladium-only catalysts [13]. In this case the reaction involves solvent-free conditions with $\mathrm{AuPd} / \mathrm{TiO}_{2}$, prepared by impregnation, and the aldehyde is formed with very high selectivities. It is somewhat surprising that the aldehyde is not reacted rapidly to the acid. In recent studies we have shown that in the case of benzyl alcohol oxidation, this is due to benzyl alcohol acting as a radical inhibitor, [27] intercepting the radicals that lead to acid formation and in turn reforming benzyl alcohol and benzaldehyde. Hence a low concentration of the alcohol can act catalytically ensuring that high aldehyde selectivities can be achieved.

The addition of palladium to gold leads to the formation of nanoparticles that are alloys. For $\mathrm{AuPd} / \mathrm{TiO}_{2}$ prepared by impregnation which has high activity and selectivity the active structures have a core-shell morphology in which there is a palladium-rich shell and a gold-rich core (Fig. 4). However, most of the gold is associated with very large particles (Fig. 4) and so it is possible that most of the metal in this catalyst formulation is not present in a high activity form. For this reason we investigated the use of sol-immobilised gold-palladium catalysts [28]. With this preparation methodology the metal nanoparticles are well dispersed and intimately alloyed (Fig. 5). For the oxidation of benzyl alcohol these materials are extremely active as catalysts (Table 1), but at the cost of lower selectivity to the aldehyde. In particular, these catalysts lead to the formation of toluene through a surface hydrogen transfer reaction and this process is particularly promoted by the presence of palladium. This effect is most marked in catalysts prepared by sol-immobilisation and is not so important for catalysts prepared by impregnation. This demonstrates that the surface composition of the alloy nanoparticles is important. The interaction with the support is also crucial and the formation of toluene can be switched-off entirely by using a basic support [29]. Solimmobilisation is a facile method of preparation that readily permits the effect of the Au:Pd ratio to be investigated (Table 2). It is apparent that the addition of small amounts of palladium to gold or vice versa leads to a significant enhancement in activity, although selectivity is not affected markedly. This synergistic effect is very important in catalysis and has yet to be explored in greater detail. Strong synergy between Au and Pd is also observed in catalysts for the direct synthesis of hydrogen peroxide [14] and the oxidation of toluene [15]. 
Recently, we have explored the addition of a third metal and we have shown that for AuPdPt catalysts the activity can be enhanced for both hydrogen peroxide synthesis [30]

Table 1 Comparison of the activity and selectivity of catalysts made by impregnation and sol-immobilisation for the oxidation of benzyl alcohol

\begin{tabular}{lll}
\hline Catalyst & $\begin{array}{l}\text { TOF } \\
\left(\mathrm{h}^{-1}\right)\end{array}$ & $\begin{array}{l}\text { Selectivity } \\
(\%)\end{array}$ \\
\hline $2.5 \% \mathrm{Au}+2.5 \% \mathrm{Pd} / \mathrm{TiO}_{2} \mathrm{IMP}$ & 3,690 & $>90$ \\
$0.5 \% \mathrm{Au}+0.5 \% \mathrm{Pd} / \mathrm{TiO}_{2} \mathrm{SI}$ & 15,360 & 70 \\
$0.5 \% \mathrm{Au}+0.5 \% \mathrm{Pd} / \mathrm{CSI}$ & 35,400 & 55 \\
\hline
\end{tabular}

Reaction conditions benzyl alcohol $(40 \mathrm{ml})$, catalyst $(0.025-0.1 \mathrm{~g})$, $120{ }^{\circ} \mathrm{C}, p \mathrm{O}_{2} 10 \mathrm{bar}$, stirring rate $1,500 \mathrm{rpm}$

Table 2 Effect of Au:Pd ratio for benzyl alcohol oxidation over solimmobilised catalysts supported on carbon

\begin{tabular}{lll}
\hline Catalyst & Conversion $(\%)$ & Selectivity $_{\text {benzaldehyde }}(\%)$ \\
\hline $1 \% \mathrm{Au}$ & 6.6 & 64 \\
$1 \%(7 \mathrm{Au}-1 \mathrm{Pd})$ & 11.6 & 66 \\
$1 \%(3 \mathrm{Au}-1 \mathrm{Pd})$ & 23.3 & 73 \\
$1 \%(2 \mathrm{Au}-1 \mathrm{Pd})$ & 52.0 & 78 \\
$1 \%(1 \mathrm{Au}-1 \mathrm{Pd})$ & 71.1 & 70 \\
$1 \%(1 \mathrm{Au}-1.85 \mathrm{Pd})$ & 80.7 & 67 \\
$1 \%(1 \mathrm{Au}-2 \mathrm{Pd})$ & 90.8 & 67 \\
$1 \%(1 \mathrm{Au}-3 \mathrm{Pd})$ & 94.7 & 67 \\
$1 \%(1 \mathrm{Au}-7 \mathrm{Pd})$ & 88.7 & 68 \\
$1 \% \mathrm{Pd}$ & 59.3 & 75
\end{tabular}

Reaction conditions benzyl alcohol $(40 \mathrm{ml})$, catalyst $(50 \mathrm{mg}), 120^{\circ} \mathrm{C}$, $\mathrm{pO}_{2} 10 \mathrm{bar}, 1,500 \mathrm{rpm}, 6 \mathrm{~h}$

Fig. 6 a HAADFimage and b the corresponding XEDS spectrum from a single AuPdPt nanoparticle supported on $\mathrm{C}$ prepared by the sol immobilization method. The ADF image and montage of $\mathrm{Au}$, $\mathrm{Pd}$ and Pt XEDS elemental maps in (c) shows the coexistence of all three elements within the nanoparticle and alcohol oxidation [18]. With benzyl alcohol oxidation, the addition of platinum switches-off the formation of toluene. For the direct synthesis of hydrogen peroxide, addition of platinum leads to a lower rate of hydrogenation of hydrogen peroxide thereby improving the overall reaction selectivity. It is possible that the formation of platinum hydride leads to these beneficial effects being observed, as this phase is more stable than palladium hydride and hence the presence of platinum inhibits particular surface hydrogen transfer processes. The AuPdPt nanoparticles are trimetallic alloys (Fig. 6) irrespective of whether they are prepared by impregnation or sol-immobilisation. While trimetallic catalysts represent an additional level of complexity, they also offer immense scope for the design of improved catalysts.

1.3 Comments on the Nature of the Active Site and the Way Forward

The observation that the catalyst activity for the synthesis of vinyl chloride from acetylene hydrochlorination correlates with the standard electrode potential led to the prediction that gold would be the best catalyst for this reaction [4]. The observation of synergistic effects for the alloying of gold and palladium for a number of reactions suggests that the activity for these reactions does not correlate with the standard electrode potential. Figure 7 shows the relevant plots for acetylene hydrochlorination, the direct synthesis of hydrogen peroxide and the oxidation of benzyl alcohol. As noted earlier, carbon is the only effective support for acetylene hydrochlorination and the correlation with the standard electrode potentials suggests that the oxidation state of gold is a key factor in this reaction and that the interfacial sites associated with the gold-carbon
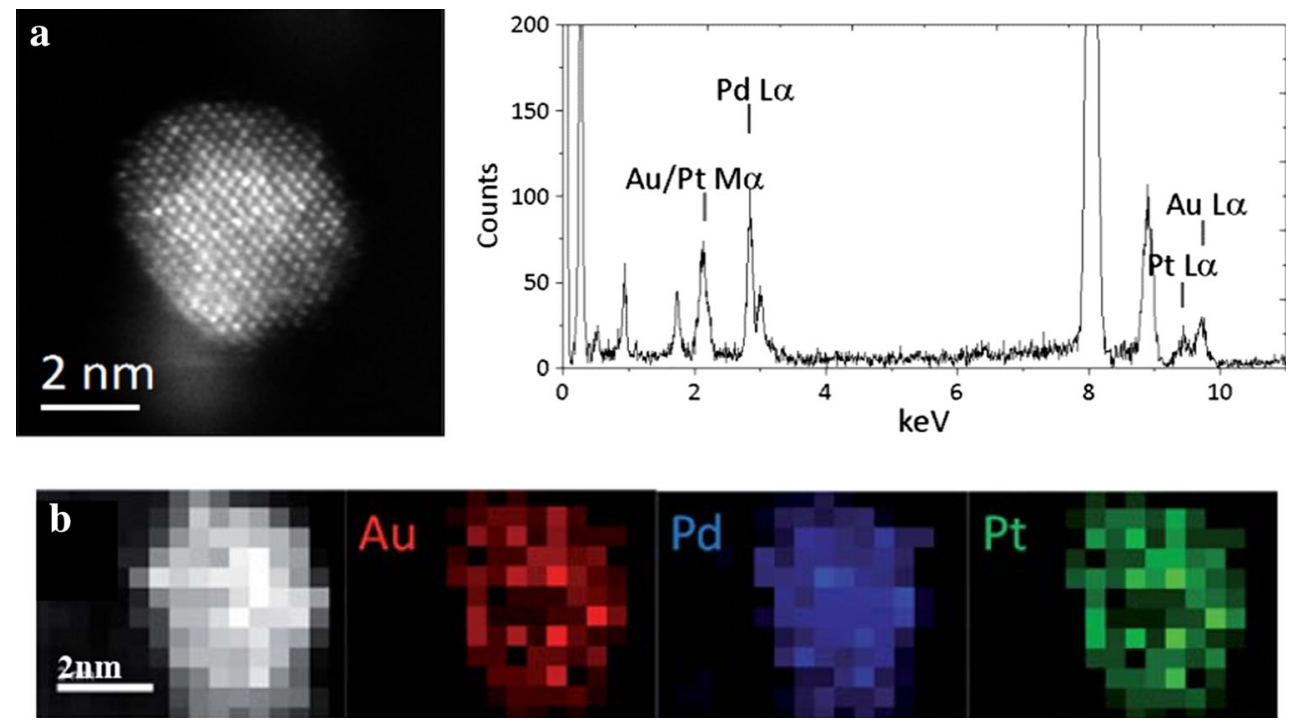


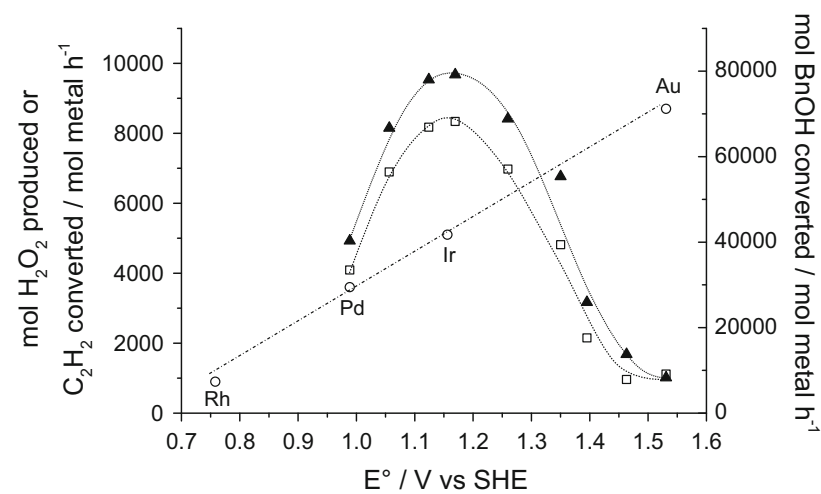

Fig. 7 Comparison of the activity of specific reactions with the standard electrode potential. Key circle acetylene hydrochlorination; filled triangle benzyl alcohol oxidation; white square direct synthesis of hydrogen peroxide

support contact points are important. With the other two redox reactions, a number of supports demonstrate efficacy and so it is possible that both the metal oxidation state and the interfacial sites may be of less significance.

It is interesting to speculate as to what developments may be possible for gold catalysis in the next 25 years. There are a number of possibilities. First we can expect that gold catalysts will be commercialised in a number of important processes. Already gold-nickel catalysts have been commercialised in the production of methyl methacrylate in Japan [31]. Given the high activity and selectivity of gold for acetylene hydrochlorination we can realistically anticipate that this will finally find commercial application. Indeed, in a recent study [32] a low content gold catalyst has been tested in pilot plant trials in China.

Another area in which we can expect to see progress concerns catalyst preparation methods. As we have noted it is non-trivialto synthesise supported gold-containing nanoparticles with the required morphologies. We can anticipate that progress will be made in the development of preparation strategies where the interfacial sites with the supporting matrix can be designed and controlled and that the morphologies of the nanoparticles engineered so that specific crystal faces with desired compositions can be prepared. In the longer term, we need to identify how we can make small 10-20 atom clusters and stabilise them under reaction conditions, as this will open up new high activity catalytic materials. Perhaps utilisation of encapsulation together with novel metal organic frameworks might offer new catalytic architectures and materials.

Given that gold and gold-containing catalysts show remarkable selectivities and activities in a range of redox reactions, particularly selective oxidation, it can be expected that supported gold catalysts could be adopted as a standard laboratory reagent for oxidation reactions at the laboratory scale. At present many such oxidations are carried out using stoichiometric oxidants, but gold catalysts can work with oxygen from air and hence are now ready to be used in a wider range of oxidation reactions for the synthesis of key intermediates.

\section{References}

1. Hashmi AKS, Hutchings GJ (2006) Angew Chem Int Ed 45:7896-7936

2. Toste FD, Michelet V (eds) (2014) Gold catalysis, an homogeneous approach. Imperial College Press, London

3. Hurata M, Kobayashi T, Sano H, Yamada N (1987) Chem. Lett 2:405-408

4. Hutchings GJ (1985) J Catal 96:292-295

5. Hayashi T, Tanaka K, Haruta M (1996) Abst Pap Am Chem Soc 211: 42-COLL

6. Prati L, Rossi M (1998) J Catal 176:552-560

7. Carrettin S, McMorn P, Johnston P, Griffin K, Hutchings GJ (2002) Chem Commun 7:696-697

8. Landon P, Collier PJ, Papworth AJ, Kiely CJ, Hutchings GJ (2002) Chem Commun 18:2058-2059

9. Fu Q, Saltsburg H, Flytzani-Stephanopoulos M (2003) Science 301:935-938

10. Abad A, Concepción P, Corma A, García H (2005) Angew Chem Int Ed 44:4066-4069

11. Hughes MD, Xu Y-J, Jenkins RL, McMorn P, Landon P, Enache DI, Carley AF, Attard GA, Hutchings GJ, King F, Stitt EH, Johnston P, Griffin K, Kiely CJ (2005) Nature 437:1132-1135

12. Corma A, Serna P (2006) Science 313:332-334

13. Enache DI, Edwards JK, Landon P, Solsona-Espriu B, Carley AF, Herzing AA, Watanabe M, Kiely CJ, Knight DW, Hutchings GJ (2006) Science 311:362-365

14. Edwards JK, Solsona B, Carley AF, Herzing AA, Kiely CJ, Hutchings GJ (2009) Science 323:1037-1041

15. Villa A, Veith GM, Prati L (2010) Angew Chem Int Ed 49:4499-4502

16. Kesavan L, Tiruvalam R, Ab Rahim MH, bin Saiman MI, Enache DI, Jenkins RL, Dimitratos N, Lopez-Sanchez JA, Taylor SH, Knight DW, Kiely CJ, Hutchings GJ (2011) Science 331:195-199

17. Ab Rahim MH, Forde MM, Jenkins RL, Hammond C, He Q, Dimitratos N, Lopez-Sanchez JA, Carley AF, Taylor SH, Willock DJ, Murphy DM, Kiely CJ, Hutchings GJ (2013) Angew. Chem Int Ed 52:1280-1284

18. He Q, Miedziak PJ, Kesavan L, Dimitratos N, Sankar M, LopezSanchez JA, Forde MM, Edwards JK, Knight DW, Taylor SH, Kiely CJ, Hutchings GJ (2013) Faraday Discuss 162:365-378

19. Hutchings GJ, Hall MS, Hutchings GJ, Carley AF, Landon P, Solsona BE, Kiely CJ, Herzing AA, Mckee M, Moulijn JA, Overweg A, Fierro-Gonzalez JC, Guzman J, Gates BC (2006) J Catal 242:71-81

20. Lopez N, Janssens TVW, Clausen BS, Xu Y, Mavrikakis M, Bligaard T, Norskov JK (2004) J Catal 223:232

21. Rashkeev SN, Lupini AR, Overbury SH, Pennycook SJ, Pantelides ST (2007) Phys Rev B 76:35438

22. Herzing AA, Kiely CJ, Carley AF, Landon P, Hutchings GJ (2008) Science 321:1331-1335

23. Hutchings GJ, Kiely CJ (2013) Acc Chem Res 46:1759-1772

24. Sankar M, He Q, Morad M, Pritchard J, Freakley SJ, Edwards JK, Taylor SH, Morgan DJ, Carley AF, Knight DW, Kiely CJ, Hutchings GJ (2012) ACS Nano 6:6600-6613

25. Nkosi B, Coville NJ, Hutchings GJ (1988) Appl Catal 43:33-39 
26. Conte M, Carley AF, Attard G, Herzing AA, Kiely CJ, Hutchings GJ (2008) J Catal 257:190-198

27. Sankar M, Nowicka E, Carter E, Murphy D, Knight DW, Bethell D, Hutchings GJ (2014) Nature Comm 5:3322

28. Pritchard J, Kesavan L, Piccinini M, He Q, Tiruvalam R, Dimitratos N, Lopez-Sanchez JA, Carley AF, Edwards JK, Kiely CJ, Hutchings GJ (2010) Langmuir 26:16568-16577

29. Meenakshisundaram S, Nowicka E, Miedziak PJ, Brett GL, Jenkins RL, Dimitratos N, Taylor SH, Knight DW, Bethell D, Hutchings GJ (2010) Faraday Discuss 145:341-356
30. Edwards JK, Pritchard J, Lu L, Piccinini M, Shaw G, Carley AF, Morgan DJ, Kiely CJ, Hutchings GJ (2014) Angew Chem Int Ed 53:2381-2384

31. Suzuki K, Yamaguchi T, Matsushita K, Iitsuka C, Miura J, Akaogi T, Ishida H (2013) ACS Catal 3:1845-1849

32. Zhou K, Jia J, Li C, Xu H, Zhou J, Luo G, Wei F (2014) Green Chem. doi:10.1039/C4GC00795F 